\title{
Pengaruh suhu terhadap mortalitas serangga hama gudang Cryptolestes ferrugineus Stephens pada inkubator
}

\section{Effect of temperature on mortality pest stored product Cryptolestes ferrugineus Stephens in incubators}

\author{
Ni Putu Eka Pratiwi ${ }^{1 *}$, Komang Dean Ananda ${ }^{1}$ \\ ${ }^{1}$ Universitas Mahasaraswati Denpasar, Indonesia \\ *Email korespondensi: ekkapratiwi@unmas.ac.id
}

Diterima: 12 Februari 2021 / Disetujui: 23 Maret 2021

\begin{abstract}
Pest stored products is greatest damage storage materials in storage areas because pest stored products have the ability to reproduce quickly, spread easily and can invite fungal growth. One of the warehouse pests that attack rice commodities, namely Cryptolestes ferrugineus. The survival and development of $C$. ferrugineus largely determines the population size when infesting the storage material. This study was conducted to determine the effect of temperature on male and female mortality and to determine the weight of the adult exposed to temperature $20^{\circ} \mathrm{C}, 25^{\circ} \mathrm{C}, 30^{\circ} \mathrm{C}, 35^{\circ} \mathrm{C}$, and $40^{\circ} \mathrm{C}$ in the incubator. The results showed that the highest mortality rate occurred since the first 24 hours of $C$. ferrugineus infestation at a temperature of $40^{\circ} \mathrm{C}$ with a humidity level of $35 \%$ to 7 days of infestation of $8.03 \%$. The temperature level did not significantly affect the weight of adult $C$. ferrugineus in the incubator.
\end{abstract}

Keywords: Cryptolestes ferrugineus, mortality, temperature, weight adult.

\section{ABSTRAK}

Hama gudang menyebabkan kerusakan bahan simpan terbesar di tempat penyimpanan karena serangga hama gudang memiliki kemampuan berkembang biak yang cepat, mudah menyebar dan dapat mengundang pertumbuhan jamur. Salah satu hama gudang yang menyerang komoditas beras yaitu, Cryptolestes ferrugineus. Ketahanan hidup dan perkembangan $C$. ferrugineus sangat menentukan jumlah populasinya saat menginfestasi bahan simpan. Penelitian ini dilakukan untuk mengetahui pengaruh suhu $20^{\circ} \mathrm{C}, 25^{\circ} \mathrm{C}, 30^{\circ} \mathrm{C}, 35^{\circ} \mathrm{C}$, dan $40^{\circ} \mathrm{C}$ terhadap mortalitas jantan dan betina serta mengetahui berat imago yang terpapar suhu di dalam Inkubator. Hasil penelitian menunjukkan bahwa rerata mortalitas tertinggi terjadi sejak 24 jam pertama infestasi imago C. ferrugineus pada suhu $40^{\circ} \mathrm{C}$ dengan tingkat kelembaban 35\% sampai 7 hari infestasi sebesar 8,03\%. Tingkatan suhu tidak berpengaruh nyata terhadap berat imago C. ferrugineus di inkubator.

Kata kunci : berat imago, Cryptolestes ferrugineus, mortalitas, suhu.

\section{PENDAHULUAN}

Beras merupakan salah satu komoditas pascapanen yang perlu mendapatkan perlakuan khusus untuk menjaga kualitas dan kuantitasnya. Beras menjadi sumber makanan pokok bagi sebagian besar masyarakat Indonesia. Proses pascapanen padi yang terdiri dari pemanenan hasil, pemrosesan gabah hingga siap di distribusikan ke konsumen, harus dilakukan secara optimum agar beras tersebut layak dikonsumsi. Pemenuhan kebutuhan beras perlu diimbangi dengan penanganan pascapanen yang baik. Proses seperti penyimpanan di gudang beras menjadi fokus utama karena pada periode tersebut beras dapat mengalami penurunan secara kuantitas dan kualitas (Andales, 1998; Syarief dan Halid, 1993).

Kerusakan beras di tingkat penyimpanan umumnya disebabkan oleh serangan hama-hama gudang seperti serangga, tungau, tikus, burung dan aktivitas pekerja di gudang penyimpanan. Hama gudang menyebabkan kerusakan bahan simpan terbesar di tempat penyimpanan karena serangga hama gudang memiliki kemampuan berkembang biak yang cepat, mudah menyebar dan dapat mengundang pertumbuhan jamur. Kerusakan yang ditimbulkan oleh serangan hama gudang seperti terjadinya susut berat, kontaminasi pada bahan simpan dan penurunan kandungan gizi.

Salah satu hama gudang yang menyerang komoditas beras yaitu, Cryptolestes ferrugineus. Serangga $C$. ferrugineus merupakan hama sekunder pascapanen pada komoditas beras dan produk komoditas pangan lainnya. Hama ini menyerang bahan simpan dalam bentuk butir pecah akibat serangan hama primer atau kerusakan akibat saat penyimpanan. Penyebaran $C$. ferrugineus meliputi daerah beriklim tropis atau iklim subtropis dengan kelembaban yang tinggi (Mason, 2003). Serangga hama C. ferrugineus dapat menyelesaikan siklus hidupnya selama 3 minggu dengan suhu optimum $35^{\circ} \mathrm{C}$ dan kelembaban $70 \%$ (Smith, 1965). Imago C. ferrugineus dapat bertahan hidup 6-9 bulan pada kondisi 
suhu optimum dan imago toleran terhadap suhu rendah jika dibandingkan dengan spesies serangga hama gudang lainnya (Fields dan White, 1997). Ketahanan hidup dan perkembangan $C$. ferrugineus sangat menentukan jumlah populasinya saat menginfestasi bahan simpan. Oleh karena itu, keberadaan serangga hama gudang $C$. ferrugineus pada tempat penyimpanan menjadi suatu permasalahan sehingga perlu dilakukan beberapa perlakuan yang tepat untuk mengendalikan serangan tersebut guna memutus atau menghambat perkembangan $C$. ferrugineus agar kondisi beras tetap layak konsumsi. Perlakukan yang akan diberikan pada penelitian ini memberi paparan beberapa tingkatan suhu dan kelembaban didalam Inkubator untuk mengetahui pengaruhnya terhadap mortalitas dari serangga hama jantan dan betina $C$. ferrugienus serta berat imago untuk dijadikan sebagai acuan dalam pengendalian di gudang penyimpanan.

\section{BAHAN DAN METODE}

\section{Pakan dan Strerilisasi Pakan}

Bahan simpan yang digunakan dalam penelitian yaitu beras varietas IR 64 . bahan disterilisasi menggunakan oven selama 4 jam dengan suhu $40^{\circ} \mathrm{C}$ kemudian didiamkan selama 24 jam pada kondisi suhu ruang $27^{\circ} \mathrm{C}$ hingga bahan tersebut siap untuk diinfestasikan serangga hama $C$. ferrugineus dan digunakan di dalam penelitian (Bekele et al., 1995). Rerata kadar air bahan yang digunakan adalah $14 \%$

\section{Perbanyakan Serangga}

Perbanyakan serangga $C$. ferrugineus dimulai dari pemeliharaan yang dilakukan di dalam tabung perbanyakan dengan suhu ruang $27^{\circ} \mathrm{C}$ dan kelembaban $70 \%$. Permukaan tabung ditutup menggunakan kain kasa. Setelah 7 hari infestasi, imago C. ferrugineus dipindahkan dari dalam tabung perbanyakan, kemudian ditunggu sampai imago F1 muncul dan siap digunakan untuk penelitian (Abebe et al., 2009).

\section{Rancangan Penelitian}

Penelitian yang dilakukan menggunakan rancangan acak lengkap dengan melakukan pengulangan sebanyak 5 kali. Penelitian menggunakan beberapa tingkat suhu dengan pengaturan di dalam Inkubator $20^{\circ} \mathrm{C}, 25^{\circ} \mathrm{C}, 30^{\circ} \mathrm{C}, 35^{\circ} \mathrm{C}$, dan $40^{\circ} \mathrm{C}$. Parameter penelitian yang diamati adalah mortalitas imago C. ferrugineus dan bobot imago baru C. ferrugineus.

\section{Mortalitas Imago C. ferrugineus}

Penelitian mortalitas imago $C$. ferrugineus diamati setiap 24 jam selama 7 hari sejak infestasi imago kedalam inkubator pada suhu $20^{\circ} \mathrm{C}, 25^{\circ} \mathrm{C}, 30^{\circ} \mathrm{C}, 35^{\circ} \mathrm{C}$, dan $40^{\circ} \mathrm{C}$. Imago yang digunakan dalam variabel penelitian ini berjumlah 15 pasang. Saat pengamatan seluruh imago $C$. ferrugineus dikeluarkan dari tabung kaca dan dihitung jumlah imago yang hidup dan mati.

\section{Berat Imago Baru C. ferrugineus}

Perhitungan berat imago baru C. ferrugineus diperoleh dari imago baru yang masih bertahan hidup dari setiap masing-masing suhu di Inkubator. Imago baru C. ferrugineus yang diperoleh diambil secara acak dari setiap tingkatan suhu $20^{\circ} \mathrm{C}, 25^{\circ} \mathrm{C}, 30^{\circ} \mathrm{C}, 35^{\circ} \mathrm{C}$, dan $40^{\circ} \mathrm{C}$. Imago yang diambil sebanyak 10 ekor untuk ditimbang berat tubuhnya menggunakan timbangan digital.

\section{Analisis Data}

Data yang diperoleh dianalisa menggunakan uji $\mathrm{F}$ dengan taraf 5\%. Apabila terdapat perbedaan diantara perlakuan dilanjutkan dengan Uji Beda Nyata Terkecil (BNT).
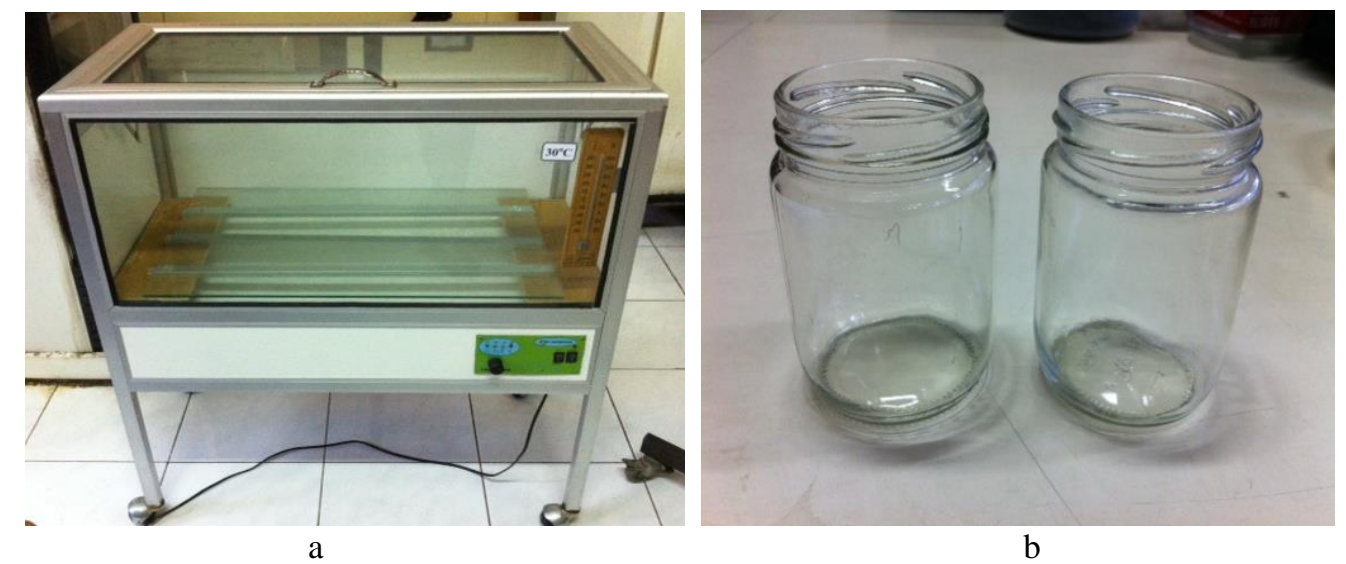

Gambar 1. Inkubator Suhu untuk Perlakuan (a), Tabung Kaca untuk Infestasi pada Setiap Perlakuan (b) 


\section{HASIL DAN PEMBAHASAN}

\section{Mortalitas Imago C. ferrugineus}

Hasil analisis statistika terhadap mortalitas imago $C$. ferrugineus menunjukkan bahwa beberapa tingkatan suhu di Inkubator berpengaruh nyata. Rerata mortalitas imago $C$. ferrugineus pada beberapa tingkatan suhu disajikan pada Tabel 1. Berdasarkan hasil penelitian yang dilakukan, menunjukkan bahwa mortalitas imago C. ferrugineus mulai terjadi sejak hari pertama setelah infestasi. Rerata mortalitas imago yang terjadi pada 24 jam pertama setelah infestasi terjadi pada suhu $20^{\circ} \mathrm{C}, 30^{\circ} \mathrm{C}$, dan $40^{\circ} \mathrm{C}$ disajikan pada Tabel 2 . Rerata mortalitas tertinggi pada 24 jam pertama setelah infestasi terjadi pada suhu $40^{\circ} \mathrm{C}$ yaitu 6 ekor dan pada suhu $25^{\circ} \mathrm{C}, 35^{\circ} \mathrm{C}$ tidak ditemukan imago $C$. ferrugineus yang mati.

Berdasarkan hasil penelitian yang dilakukan rerata mortalitas imago jantan dan betina pada paparan suhu $20^{\circ} \mathrm{C}$, $25^{\circ} \mathrm{C}, 30^{\circ} \mathrm{C}, 35^{\circ} \mathrm{C}$, dan $40^{\circ} \mathrm{C}$ disajikan pada Tabel 3. Hasil analisis statistika terhadap mortalitas jantan dan betina C. ferrugineus menunjukkan bahwa beberapa tingkatan suhu di Inkubator berpengaruh nyata. Nilai kelembaban yang ditampilkan pada Tabel 1. alami mengikuti perlakuan suhu yang terjadi pada masing-masing inkubator tanpa rekayasa.

\section{Berat Imago Baru C. ferrugineus}

Hasil analisis statistika terhadap berat imago baru $C$. ferrugineus menunjukkan bahwa beberapa tingkatan suhu di Inkubator tidak berpengaruh nyata. Pengukuran berat imago baru C. ferrugineus tidak dapat dilakukan pada suhu $40^{\circ} \mathrm{C}$ karena telur yang berada pada suhu tersebut tidak dapat berkembang hingga menjadi imago baru. Berat imago baru $C$. ferrugineus pada beberapa tingkatan suhu ruang disajikan pada Tabel 3.

\section{Mortalitas Imago C. ferrugineus}

Beberapa spesies hama gudang tidak dapat bertahan hidup pada waktu lebih dari 24 jam pada suhu $40^{\circ} \mathrm{C}$ (Fields, 1992) pernyataan tersebut sesuai dengan penelitian yang dilakukan bahwa pada suhu $40^{\circ} \mathrm{C}$ di hari pertama selama 24 jam infestasi imago $C$. ferrugineus telah mengalami mortalitas sebesar 6 ekor (Tabel 2). Suhu $40^{\circ} \mathrm{C}$ pada 24 jam pertama pengamatan mengalami rerata mortalitas paling tinggi dibandingkan dengan rerata mortalitas pada suhu lainnya yaitu sebesar 6 ekor dan pada suhu $25^{\circ} \mathrm{C}, 35^{\circ} \mathrm{C}$ tidak ditemukan imago yang mati pada 24 jam pertama. Puncak mortalitas imago C. ferrugineus selama 7 hari infestasi terjadi pada suhu $40^{\circ} \mathrm{C}$ dengan rerata mortalitas $8,03 \%$. Berdasarkan hasil analisis statistika rerata mortalitas terendah imago $C$. ferrugineus terjadi pada suhu $35^{\circ} \mathrm{C}$ yaitu sebesar $2,02 \%$.

Tabel 1. Rerata Mortalitas Imago C. ferrugineus pada Beberapa Tingkatan Suhu di Inkubator

\begin{tabular}{lcc}
\hline Perlakuan Suhu & Kelembaban & Rerata Mortalitas Imago $(\%)$ \\
\hline $20^{\circ} \mathrm{C}$ & $60 \%$ & $3,18 \mathrm{ab}$ \\
$25^{\circ} \mathrm{C}$ & $70 \%$ & $3,92 \mathrm{ab}$ \\
$30^{\circ} \mathrm{C}$ & $68 \%$ & $4,19 \mathrm{~b}$ \\
$35^{\circ} \mathrm{C}$ & $40 \%$ & $2,02 \mathrm{a}$ \\
$40^{\circ} \mathrm{C}$ & $35 \%$ & $8,03 \mathrm{c}$ \\
\hline
\end{tabular}

Keterangan : Angka yang didampingi huruf yang sama pada kolom yang sama menunjukan tidak berbeda nyata berdasarkan uji BNT 5\%.

Tabel 2. Rerata Mortalitas Imago dalam Waktu 24 Jam Setelah Infestasi ke Inkubator

\begin{tabular}{lc}
\hline Perlakuan Suhu & Rerata Mortalitas Setelah 24 Jam Infestasi (Ekor) \\
\hline $20^{\circ} \mathrm{C}$ & 0,6 \\
$25^{\circ} \mathrm{C}$ & 0 \\
$30^{\circ} \mathrm{C}$ & 0,6 \\
$35^{\circ} \mathrm{C}$ & 0 \\
$40^{\circ} \mathrm{C}$ & 6 \\
\hline
\end{tabular}

Tabel 3. Jumlah dan Jenis Kelamin Imago C. ferrugineus yang Mengalami Mortalitas

\begin{tabular}{lcc}
\hline Perlakuan Suhu & Rerata Mortalitas Jantan (ekor) & Rerata Mortalitas Betina (ekor) \\
\hline $20^{\circ} \mathrm{C}$ & $1,20 \mathrm{abc}$ & $0,20 \mathrm{a}$ \\
$25^{\circ} \mathrm{C}$ & $1,80 \mathrm{~cd}$ & $0,20 \mathrm{a}$ \\
$30^{\circ} \mathrm{C}$ & $1,20 \mathrm{abc}$ & $1,40 \mathrm{c}$ \\
$35^{\circ} \mathrm{C}$ & $0,40 \mathrm{ab}$ & $0,40 \mathrm{ab}$ \\
$40^{\circ} \mathrm{C}$ & $14,00 \mathrm{e}$ & $8,60 \mathrm{~d}$ \\
\hline
\end{tabular}

Keterangan : Angka yang didampingi huruf yang sama pada kolom yang sama menunjukan tidak berbeda nyata berdasarkan uji BNT 5\%. 
Tabel 3. Berat imago baru C. ferrugineus pada beberapa tingkatan suhu di inkubator.

\begin{tabular}{lc}
\hline Perlakuan Suhu & Berat Imago Baru (mg) \\
\hline $20^{\circ} \mathrm{C}$ & 0,96 \\
$25^{\circ} \mathrm{C}$ & 0,97 \\
$30^{\circ} \mathrm{C}$ & 0,83 \\
$35^{\circ} \mathrm{C}$ & 0,89 \\
$40^{\circ} \mathrm{C}$ & - \\
\hline
\end{tabular}

Keterangan : - Data ditransformasi ke akar untuk keperluan analisis statistika dengan = SQRT (data asli+0,5).

A

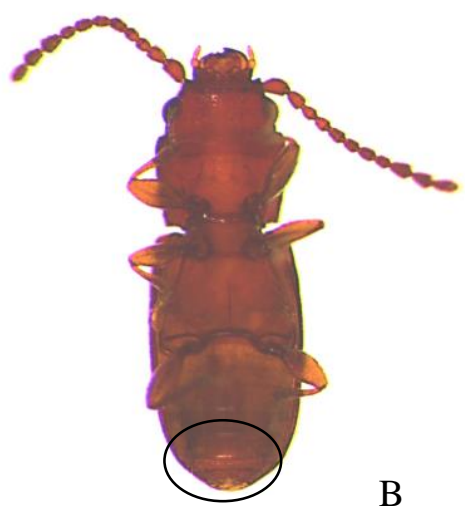

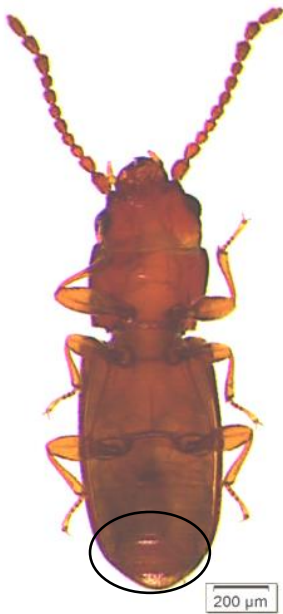

Gambar 2. imago jantan C. ferrugineus (a), imago betina C. ferrugineus (b)
Suhu $40^{\circ} \mathrm{C}$ membuat stress bagi beberapa serangga hama gudang karena terdapat tekanan dan tingkat oksigen yang tidak sesuai bagi hama gudang untuk bertahan hidup (Burks et al., 2000). Berdasarkan hasil penelitian Mbata (2001) menunjukkan bahwa serangga hama gudang Plodia interpunctella akan mengalami stress terutama pada perlakuan suhu tinggi tanpa perlu adanya tambahan perlakuan yang lain. Pemberian perlakuan suhu untuk mortalitas serangga hama gudang yang disimpan umumnya memerlukan suhu mendekati $50^{\circ} \mathrm{C}$ selama berjam-jam namun suhu tersebut tidak merusak produk makanan (Burks et al., 2000). Berdasarkan hasil penelitian Qader (2011) menunjukkan bahwa paparan suhu $35^{\circ} \mathrm{C}$ pada imago Tribolium castaneum selama 65 menit memiliki tingkat mortalitas $0,0 \%$ hal tersebut sesuai dengan penelitian yang dilakukan karena pada pengamatan $24 \mathrm{jam}$ pertama pada suhu $35^{\circ} \mathrm{C}$ tidak terjadi mortalitas pada serangga hama $C$. ferrugineus. Suhu optimum bagi $C$. ferruginues untuk berkembang biak adalah $35^{\circ} \mathrm{C}$ dengan tingkat kelembaban $70 \%$ memerlukan waktu untuk masa perkembangan paling singkat selama 21 hari (Rees, 2004).

Berdasarkan hasil penelitian yang dilakukan imago jantan C. ferrugineus lebih peka terhadap beberapa tingkatan suhu di Inkubator daripada imago betina, hal tersebut tampak dari rerata imago jantan yang mati lebih tinggi dibandingkan dengan imago betina pada setiap perlakuan suhu (Tabel 3). Pada tabel 3 disajikan perbandingan rerata mortalitas imago jantan dan imago betina pada suhu $35^{\circ} \mathrm{C}$ yang rerata kematiannya sama, hal ini menunjukkan bahwa suhu optimum bagi serangga hama $C$. ferrugineus sangat berperan penting dalam mempertahankan hidupnya baik bagi imago jantan maupun imago betina. Pada suhu $40^{\circ} \mathrm{C}$ imago jantan mengalami mortalitas paling tinggi sebesar 14,00 ekor dibandingkan dengan mortalitas imago jantan pada perlakuan suhu lainnya dan imago betina mengalami mortalitas sebeasar 8,60 ekor, hal tersebut terjadi karena suhu $40^{\circ} \mathrm{C}$ merupakan suhu diluar batas optimum bagi $C$. ferrugineus sehingga mortalitas jantan dan betina paling tinggi jika dibandingkan pada suhu lainnya. Imago betina $C$. ferrugineus memiliki energi metabolik yang digunakan untuk melalukan peletakan telur sehingga imago betina lebih toleran pada kondisi suhu tertentu untuk dapat bertahan hidup jika dibandingkan dengan imago jantan C. ferrugineus (Kawamoto, 1989).

Mortalitas imago $C$. ferrugineus yang terjadi pada beberapa tingkatan suhu di Inkubator akan memengaruhi jumlah imago baru yang muncul, karena imago tidak sempat meletakan telur jika sudah terjadi mortalitas sejak hari pertama seperti pada suhu $20^{\circ} \mathrm{C}, 30^{\circ} \mathrm{C}$, dan $40^{\circ} \mathrm{C}$. Mortalitas paling tinggi terjadi pada suhu $40^{\circ} \mathrm{C}$ yaitu sebesar $8,03 \%$ jika dibandingkan dengan suhu lainnya. Smith (1965), menyatakan bahwa akan terjadi peningkatan mortalitas imago C. ferrugineus hingga $60 \%$ pada suhu ekstrim seperti suhu $20^{\circ} \mathrm{C}$ dan $40^{\circ} \mathrm{C}$. Kisaran suhu $30^{\circ} \mathrm{C}-35^{\circ} \mathrm{C}$ dengan tingkat kelembaban $70 \%$ - 90\% akan menjadi kondisi optimum bagi 
serangga hama $C$. ferrugineus untuk berperan sebagai hama gudang.

\section{Berat Imago Baru C. ferrugineus}

Berdasarkan hasil penelitian yang dilakukan berat imago baru pada masing-masing suhu di inkubator tidak berpengaruh nyata. Berdasarkan hasil penelitian sakka (2018) rerata berat imago Triboium castaneum pada suhu $22^{\circ} \mathrm{C}$, $27^{\circ} \mathrm{C}$, dan $32^{\circ} \mathrm{C}$ pada beras merah tidak berpengaruh nyata.

\section{KESIMPULAN}

Berdasarkan hasil penelitian yang dilakukan pada beberapa tingkat suhu di Inkubator terhadap mortalitas menunjukkan bahwa mortalitas tertinggi terjadi pada suhu $40^{\circ} \mathrm{C}$ dengan tingkat kelembaban $35 \%$ sebesar $8,03 \%$ dibandingkan dengan suhu lainnya. Rerata mortalitas tertinggi terjadi pada imago jantan $C$. ferrugineus pada setiap suhu perlakuan jika dibandingkan dengan imago betina. Puncak rerata mortalitas imago jantan $C$. ferrugineus terdapat pada suhu $40^{\circ} \mathrm{C} 14,00$ ekor dan imago betina $C$. ferrugineus 8,60 ekor.

\section{SARAN}

Pengaturan suhu gudang yang tidak optimum bagi serangga hama gudang $C$. ferrugineus dapat diterapkan digudang penyimpanan beras guna meningkatkan mortalitas dan memutus siklus hidup untuk menguranngi dampak buruk yang ditimbulkan terhadap bahan simpan.

\section{DAFTAR PUSTAKA}

Abdelghany, A. Y., \& G. F. Paul. (2017). Mortality and movement of Cryptolestes ferrugineus and Rhyzopertha dominica in response to cooling in 300$\mathrm{kg}$ grain bulks. Journal of Stored Products Research 71, 119-124.

Abebe, F., T. Tefera, S. Mugo, Y. Beyene \& S. Vidal. (2009). Resistence of Maize Varieties of the Maize Weevil $S$. zeamais. African Journal of Biotechnology. 8(21), 5937-5943.

Andales, S. C. (1988). Summary Rerquirements for Safe Grain Storage. In Sample R. L. et al. (Ed). Towards Integrated Commodity and Pest Management in Grain Storage. Proceedings and Selected Papers from the Regional Training Course on Integrated Pest Management Strategies in Grain Storage Systems. Philippines: National Post Harvest Institute for Research and Extension (NAPHIRE), Departement of Agriculture.

Astuti, L. P., G. Mudjiono, S. Rasminah \& B. T. Rahardjo. (2013). Influence of Temperature and Humidity on the Population Growth of Rhyzopertha dominica (f.)
(Coleoptera: Bostrichidae) on Milled Rice. Journal of Entomology. 10 (2), 86-94.

Bekele, J. A., D. Obengofori, A. Hassanali \& G. H. N. Nyamasyo. (1995). Products Derived from the Leaves of Ocimum kilimandscharicum as Post-Harvest Grain Protectants Againts the Infestation of Three Major Stored Product Insect Pests. Bulletin Entomology. Res., 85, 361-367.

Burks, C. S., J. A. Johnson, D. E. Maier, \& J. W. Heaps. (2000). Temperature, pp. 73Đ104. In B. Subramanyam and D. W. Hagstrum [eds.], Alternatives to pesticides in storedproduct IPM. Kluwer, Boston, MA

Fields, P. G. (1992). The control of stored-product insects and mites with extreme temperature. Journal Stored Product. Res. 28, 89-118.

Fields, P. G., \& N. D. G. White. (1997). Survival and multiplication of stored-product beetles at simulated and actual winter temperatures. Can. Entomol. 129: 887-898.

Flinn, P.W., \& D. W. Hagstrum. (1998). Distribution of Cryptolestes ferrugineus (Coleoptera: Cucujidae) in response to temperature gradients in stored wheat. Journal Stored Product. Res. 34, 107-112.

Howe, R. W. (1956). The Effect of Temperature and Hunidity on Rate of Development and Mortality of Tribolium Castaneum (Herbest) (Coleoptera : Tenebrionidae). Annual Applied Biology. 44(2), 356368

Jian, F., Jayas, D., \& N. D. G. White. (2004). Movement and distribution of adult rusty grain beetle, Cryptolestes ferrugineus (Coleoptera: Laemophloeidae), in stored wheat in response to different temperature gradients and insect densities. J. Econ. Entomol. 97, 1148-1158

Kawamoto, H. (1989). Effect of Temperature on Adult Survival and Potential Fecundity of The Rusty Grain Beetle Cryptolestes ferrugineus. Japanese Society of Applied Entomology and Zoology. 24, 418-423.

Kumawat, K. C. (2007). Effect of Abiotic Factors on Biology of Rhyzopertha dominica on Wheat. Annual Plant Protection Science. 15, 111-115

Lee Jr., \& R. E. Denlinger. (1991). Principles of insect low temperature tolerance. In: Lee Jr., R.E., Denlinger, D.L. (Eds.), Insects at Low Temperature. Chapman and Hall, New York, pp. 17-46.

Mason, L. J., \& C. A. Strait. (1998). Stored product integrated pest management with xtreme temperatures. In: 
Denlinger, D.L., Yocum, G.D. (Eds.), Physiology of Heat Sensetitive. Westview Press, Boulder, pp. 7-57.

Mason, L. J. (2003). Grain Insect Fact Sheet E-227-W: Rusty, Flat, and Flour Mill Beetles Cryptolestes spp. Purdue University, Department of Entomology.

Mbata, G. N., \& W. P. Thomas. (2001). Effect of Temperature and Exposure Time on Mortality of Stored-Product Insects Exposed to Low Pressure. Entomology Society of America. 95 (5), 1302-1307

Qader, F. A. (2011). The Effect of Low and Highly Temperatire Degree on Red Rust Flour Beetle Tribolium Castaneum (Tenebrionidae: Coleoptera). Scientific International Virtual Agriciltural Conference
Rees, D. (2004). Insects of Stored Products. CSIRO Publishing, Collingwood, Australia.

Rilett, R. O. (1949). The biology of Laemophloeus ferrugineus (Steph). Can. J. Res. 27, 112-148.

Sinha, R. N., \& F. L. Watters. (1985). Insect Pests of Flour Mills, Grain Elevators, and Feed Mills and Their Control. Research Branch, Agriculture Canada Publication 1776, Ottawa, Ontario

Smith, L. B. (1965). The intrinsic rate of natural increase of Cryptolestes ferrugineus (Stephens) (Coleoptera: Cucujidae). Journal Stored Product. Res. 1, 35-49.

Syarief, R., \& H. Halid. (1993). Teknologi Penyimpanan Pangan. Jakarta: Penerbit Arcan. 